\title{
Effect of Corrugation Angle in Strength of Trapezoidal Corrugated Web Steel Built-up Beam
}

\author{
Dhruv Narola $^{1}$, Anuj Meena ${ }^{1}$, Kanika Meena ${ }^{1}$, Apurva Dave $^{\mathbf{1}}$ \\ ${ }^{1}$ Pandit Deendayal Petroleum University \\ Gandhinagar, Gujarat, India
}

dhruvnarola1998@gmail.com; anuj.mcv15@ sot.pdpu.ac.in; kanika.mcv15@ sot.pdpu.ac.in; apurva.dave@ sot.pdpu.ac.in

\begin{abstract}
The aim of this research is to find out the effect of corrugation angle in trapezoidal corrugated web steel built-up beam via experimental data of load vs. deflection curve, load carrying capacity, central vertical deflection and lateral displacement on simply supported beam by the application of point load at the center of the beam. Prepared specimen by using hot rolled steel plate having thickness $1.2 \mathrm{~mm}$ for the flange and $0.2 \mathrm{~mm}$ for the web for varying corrugation angle. Three different corrugation angles as a $25^{0}, 30^{0} \&$ $35^{0}$ were taken and compared its effect on the load carrying capacity and central maximum deflection of the beam. The experimental data is compared with the finite element method based software ANSYS and it was found that the experimental data agreed with ANSYS results.
\end{abstract}

Keywords: Corrugated web, trapezoidal, Corrugation angle, simply supported condition, point load, load carrying capacity, central vertical deflection and Lateral displacement.

\section{Introduction}

The I-section beams are commonly used in structural steel works. The web usually bears most of the compressive stress and transmits shear in the beam while the flanges support the major external loads [6]. Thus, by using a greater part of the material for the flanges and thinner web, materials saving could be achieved without weakening the load-carrying capability of the beam [7]. As the compressive stress in the web has exceeded the critical point prior to the occurrence of yielding, the flat web loses its stability and deforms transversely. This could be improved by using the corrugated web, an alternative to the plane web [1]. The main benefits of this type of beams are that the corrugated webs increase the beam's stability against buckling and sufficient reduction in weight with light gauge elements $[4,8]$, which may result in an economical design via the reduction of web stiffeners. In addition critical moment also increases by $40 \%$ with trapezoidal corrugation of the web [9]. The use of trapezoid web has also found to lower the stress concentration at the web-flange welded connection and hence increase the fatigue strength [10]. The corrugated steel webs fail due to shear buckling or yielding, and three different shear buckling modes (local, global, and interactive) are possible depending on the geometric characteristics of corrugated steel webs. However, for I-girders with corrugated steel webs, the bending is the major design aspect, and it is crucial to thoroughly understand the flexural-torsional buckling of the I-girder with corrugated steel webs [3].In this paper study carried out on the impact of corrugation angle on Load-carrying capability and deflection of beams with trapezoidal web corrugation.

\section{Material and Method}

\subsection{Test specimens}

Three models of steel built-up beams with varying corrugation angle of the trapezoidal corrugated web were selected for the experimental tests and designated as TCW-1, TCW-2and TCW-3. The detail dimensions and specification of these test specimens are given in Table.1 and illustrated in Fig.1. The flanges were made from galvanized iron hot rolled sheet of $85 \mathrm{~mm}$ wide and $1.2 \mathrm{~mm}$ thickness and webs were made from the same material but width $155 \mathrm{~mm}$ and thickness of $0.2 \mathrm{~mm}$. The flange and web were joined with L-section using resistance spot welding. The electrode tip diameter was $12 \mathrm{~mm}$ and 3 weld spots were placed per L-section at 50 Ampere current. 
Table 1. Test specimens dimension.

\begin{tabular}{|c|l|l|l|l|l|l|l|}
\hline Profile & $\begin{array}{c}\text { Length of } \\
\text { web(mm) }\end{array}$ & $\begin{array}{c}\text { Length of } \\
\text { flange(mm) }\end{array}$ & $\begin{array}{c}\text { Corrugation } \\
\text { angle( }(\boldsymbol{\alpha})\end{array}$ & $\mathbf{b}(\mathbf{m m})$ & $\mathbf{d}(\mathbf{m m})$ & $\mathbf{a}(\mathbf{m m})$ & $\mathbf{h}(\mathbf{m m})$ \\
\hline TCW -1 & 910 & 860 & $25^{0}$ & 115 & 75 & 80 & 35 \\
\hline TCW -2 & 910 & 860 & $30^{0}$ & 115 & 60 & 70 & 35 \\
\hline TCW-3 & 910 & 860 & $35^{0}$ & 115 & 50 & 60 & 35 \\
\hline
\end{tabular}

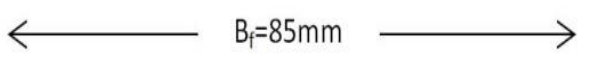

$\mathrm{t}_{\mathrm{f}}=1.2$
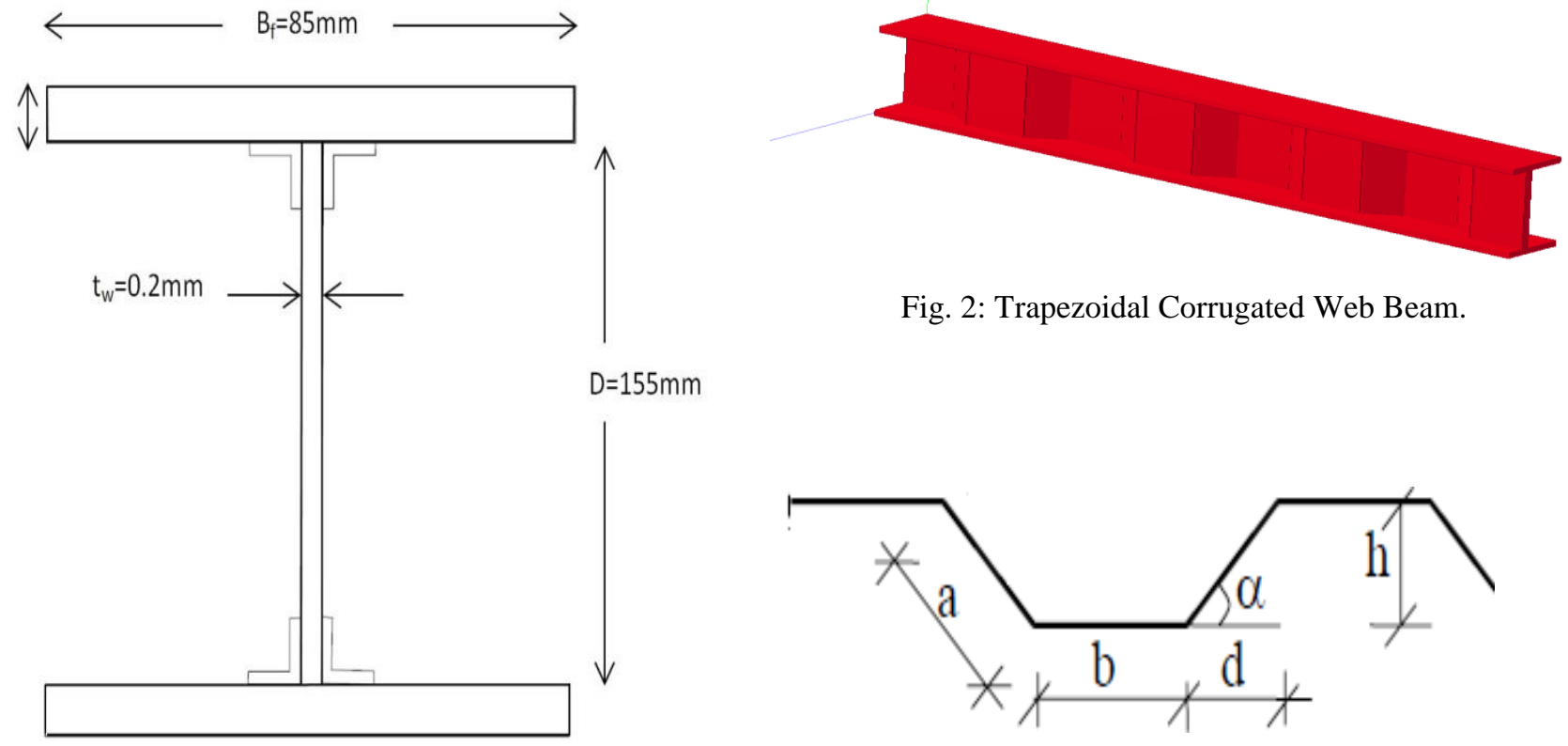

Fig. 2: Trapezoidal Corrugated Web Beam.

Fig. 1: Section of beam.

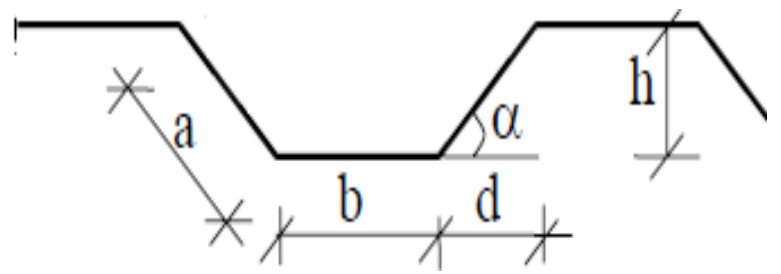

Fig. 3: Dimension of web.

\subsection{Test Setup}

A test rig was designed as the base support for the test specimens and providing the three-point bending condition as shown in Fig. 5. The rig is rigid and undistorted under the action of loading. The test set-up consists of the hydraulic jack with digital display having capacity of $30 \mathrm{KN}$.

\subsection{Loading and Measurement}

The tests on the specimen under bending load were carried out in Structure Laboratory of Pandit Deendayal Petroleum University. The specimens were simply supported with a span of $860 \mathrm{~mm}$ long and a concentrated load was applied on the center of the top flange using a manual hydraulic jack and load shell. The dial gauge with the least count of $0.01 \mathrm{~mm}$ was used to measure the displacement in vertical as well as in a horizontal direction. Gauges were installed to measure vertical deflection at the mid-span of the beam, also installed to measure the lateral displacements at the middle of the steel web in center span. In addition, gauges were located at the supported bottom flange in the vertical direction at one-fourth of the span length and at an upper flange at one-fourth of the span middle section in the lateral direction, to ascertain the uneven settlement and to check lateral torsional twist of the beam as shown in the fig. 4 . 


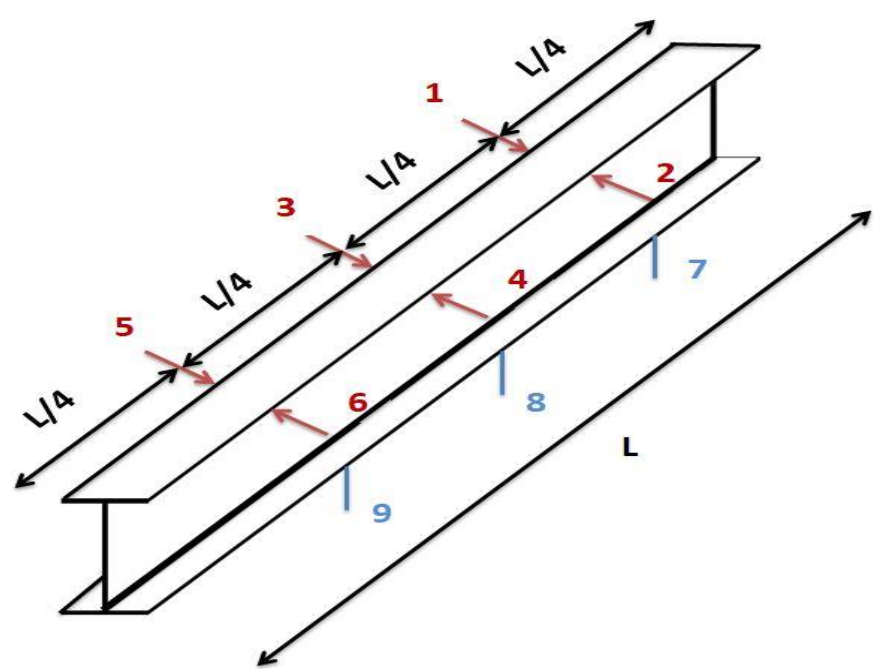

Fig. 4: Alignment of dial gauge.

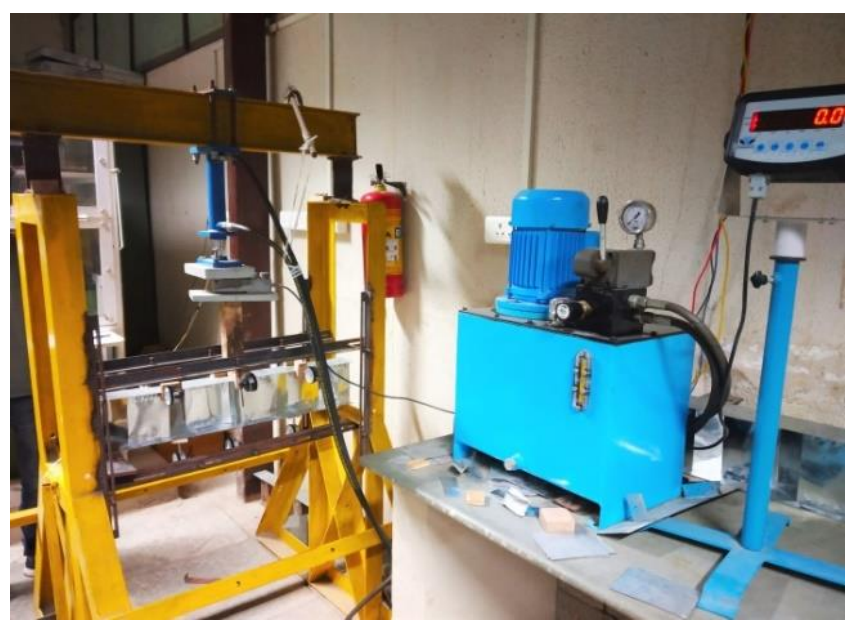

Fig. 5: Test setup.

\section{Results}

The comparison between TCW-1, TCW-2 and TCW-3 for their load carrying capacity, central vertical deflection and lateral deflection is shown in Fig. 6, $7 \&$ \& . It shows that as the Corrugation angel increases $\left(25^{0}, 30^{0}, 35^{\circ}\right)$ there is a considerable strength increase against bending and lateral torsional buckling. It was found that corrugated web with $35^{\circ}$ corrugation angle has $32 \%$ and $10 \%$ higher load carrying capacity then $25^{\circ}$ and $30^{\circ}$ respectively. While making specimen there could be a possible error due to improper weld bid, whereas while taking reading of deflection, there could be human error while reading analog dial gauge.

Table 2: Experiment Result.

\begin{tabular}{|c|c|c|c|c|}
\hline Profile & $\begin{array}{c}\text { Load carrying } \\
\text { capacity(N) }\end{array}$ & $\begin{array}{c}\text { Central } \\
\text { Vertical } \\
\text { Deflection(mm) }\end{array}$ & $\begin{array}{c}\text { Lateral displacement } \\
\text { (Gauge 1)(mm) }\end{array}$ & $\begin{array}{c}\text { Lateral displacement } \\
\text { (Gauge 6)(mm) }\end{array}$ \\
\hline TCW-1 & 245 & 4.02 & 3.76 & 3.17 \\
\hline TCW-2 & 325 & 4.13 & 3.90 & 3.41 \\
\hline TCW-3 & 360 & 3.85 & 2.12 & 2.67 \\
\hline
\end{tabular}

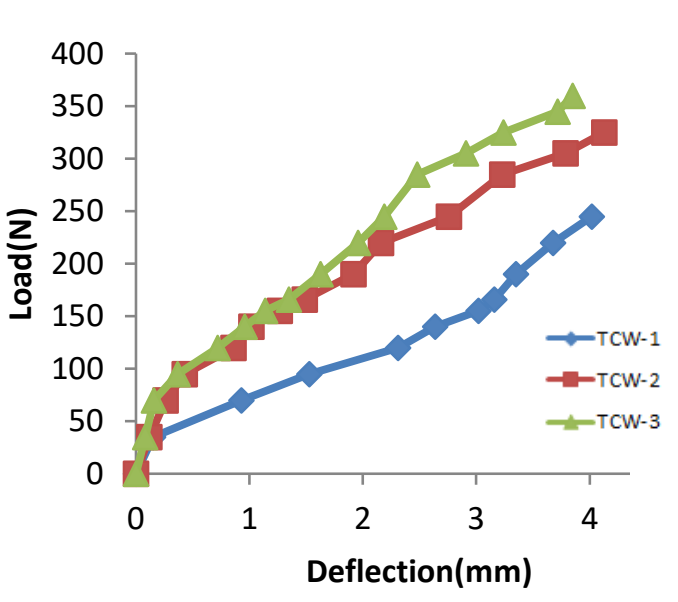

Fig. 6: Load vs. Central vertical deflection.

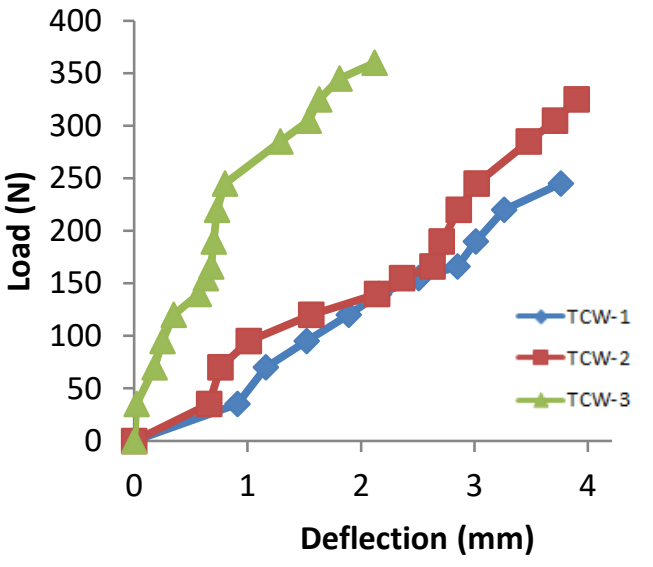

Fig. 7: Load vs. lateral displacement (Gauge 1).

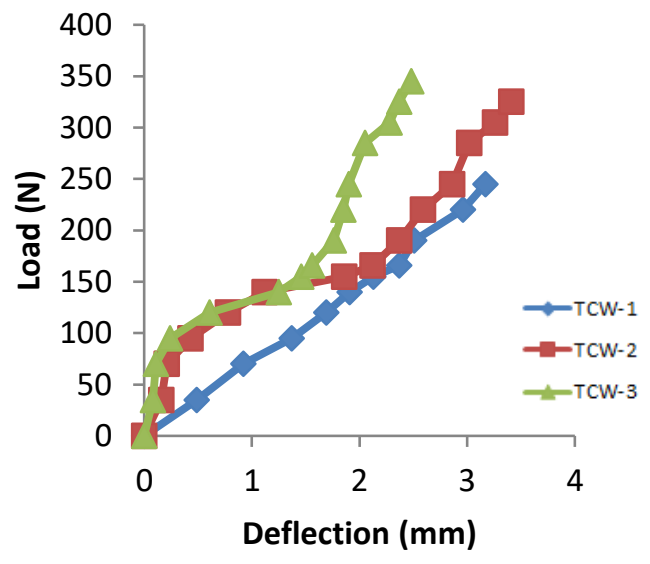

Fig. 8: Load vs. lateral displacement (Gauge 6). 


\section{Conclusion}

In this research, the strength of trapezoidal corrugated web steel built-up beam with different corrugation angle has been studied. When the vertical load applied on the center of the beam it results in compression in upper flange and tension in lower flanges of the section. Tension flange supports member to stay straight whereas the compression flange tries to deflect laterally from its original position. From the above results, we can conclude that lateral displacement occurred in the compression flange. In TCW-3 profile less lateral displacement observed than TCW-1 and TCW-2. Here the compression flange is free to displace laterally and rotate. When an applied load causes both lateral displacement and twisting of a member lateral torsional buckling has occurred. The lateral torsional buckling affected by the distance between the shear center of the beam and location at an application of load. From the above results, we can interpretate that with an increase in the corrugation angle in the strength of the beam.

\section{References}

[1] Dan Dubina, Viorel Ungurenu, LuCian Gllia, "Experimental investigations of cold-formed steel beams of corrugated web and built-up section for flanges," Thin-Walled Structure, vol. 90, pp. 159-170, 2015.

[2] Jun He, Yuqing Liu, Airong Chen, Dalei Wang, Teruhiko Yoda "Bending behavior of concrete-encased composite Igirder with corrugated steel web," Thin-walled structures, vol.74, pp. 70-84, 2014.

[3] Jongwon Yi, Heungbe Gil, Gil H, Kwangsoo Youm, Hakeun Lee, "Interactive Shear buckling behavior of trapezoidally corrugated strength of trapezoidal corrugated Steel webs," Engineering Structures, vol. 30, pp. 1659-1666, 2008.

[4] Sayed-Ahmed E. Y. "Lateral torsion buckling behavior of hot-rolled steel I-girders with plain and corrugated webs," in Proceedings Of The Institution Of Civil Engineers. Structures And Buildings, vol. 158, no. 1, pp. 53-69, 2005.

[5] De'nan. F. M. "The Effect of web Opening On Lateral Torsion Behavior of Triangular Web Profile Steel Beam Section," International Conference on Science Technology \& Social Science, 2012.

[6] Y. A. Khalid, C. L. Chan, B. B. Sahari, A. M. S. Hamouda, "Bending behavior of corrugated web beams," Journal of Materials Processing Technology, vol. 150, no. 3, pp. 242-254, 2004.

[7] W. Zhang, Y. Li, Q. Zhou, X. Qi, G. E. O. Widera, "Optimization of the structure of an H-beam with either a flat or a corrugated web," Part 3, Journal of Materials Processing Technology vol. 101, no. 1, pp. 119-123, 2000.

[8] A. Limaye and P. M. Alandkar, "Strength Of Welded Plate Girder With Corrugated Web Plate," International Journal of Engineering Research and Applications, vol. 3, pp. 1925-1930, 2013.

[9] H. R. Kazemi, Nia Korrani, S. Molanaei, "The Effect of the Corrugation Profiles of the Web and the Lateral Torsion Buckling Strength of the Inelastic I-Girder," World Applied Science Journal, vol. 8, no. 5, pp. 427-530, 2010.

[10] Mutasim E. Ibrahim, "Behavior of hot-rolled steel plate girders with trapezoidal corrugated webs under fatigue loading," International Journal for Research in Applied Science \& Engineering Technology, 2006.

[11] Tahir M. Sulaimana, "Experimental tests on composite and non- composite connections using trapezoid web profiled steel sections," International journal of Steel Structure, pp. 43-58, 2008. 